\title{
ESTÉTICA TOMASIANA Y ESTÉTICA MUSULMANA PLENOMEDIEVALES. A PROPÓSITO DEL PULCHRUM
}

\author{
Josep-Ignasi Saranyana \\ Universidad de Navarra
}

\section{RESUMEN}

Algunos neotomistas afirman la trascendentalidad de pulchrum. Se ha dicho que esta posición neotomista es un anacronismo, porque refleja los puntos de vista de la Ilustración proyectados sobre la auténtica síntesis tomasiana. En Aquino, en efecto, no aparece claramente admitida esa trascendentalidad. Sin embargo, parece insinuada, al tratar el par subpredicamental forma-figura, pero trascendiendo el orden categorial. Por ello, algunos tomistas hablan de un «trascendental-dependiente», cognoscible por vía sensitiva, equiparando, de alguna manera, el sensus a la ratio. En esto coincidirían la filosofía aquiniana con la filosofía musulmana plenomedieval.

Palabras clave: Tomás de Aquino, pulchrum, trascendental.

\section{ABSTRACT}

Some neothomist philosophers affirm the transcendentality of «pulchrum», but this thesis is not clearly expossed by St. Thomas of Aquino, though he certainly hints it. That's why some thomist philosophers speak of transcendental thought known by sensitiva way, equalizing in this manner the «sensus» to the «ratio». In this point St. Thomas' philosophy and Muslim philosophy are similar.

Key words: Thomas of Aquino, Pulchrum, Transcendental.

\section{TRASCENDENTAL, SUPRA-TRASCENDENTAL Y TRASCENDENTAL- DEPENDIENTE}

En su estudio sobre «el ser como primer trascendental», Jan A. Aertsen recuerda cosas muy fundamentales y no, por ello, demasiado sabidas ${ }^{1}$. Realiza, además, una notable crítica del pulchrum como «trascendental olvidado», según la conocida expresión de Étienne Gilson ${ }^{2}$. Como se sabe, Gilson despertó el interés de los tomistas hacia ese supuesto trascendental, de

1 Jan A. AERTSEN, Medieval philosophy and the transcendentals. The case of Thomas Aquinas, J. Brill, Leiden 1996. Seguimos la traducción española: Los trascendentales en la Edad Media, EUNSA, Pamplona, 2003 , cap. IV, \& 1 .

2 Ibidem, cap. VIII, $\S 1$ : «La cuestión de la trascendentabilidad de la belleza en Tomás nos enfrenta a una considerable paradoja. La discusión de la belleza ocupa un lugar marginal en su trabajo; en ningún sitio le dedica una quaestio separada a este asunto. En ninguno de los tres textos básicos sobre los trascendentales (ver tema II) se menciona la belleza como una propiedad trascendental. Gilson ha hablado respecto de esto de un «trascendental olvidado» (Étienne Gilson, Elements of Christian Philosophy, New York, 1960, pp. 159-63: «The. Forgotten Transcendental: Pulchrum»). 
modo que ahora muchos medievalistas sostienen que la belleza tiene estatuto trascendental también en la metafísica tomasiana ${ }^{3}$.

Por todo ello, conviene recordar primeramente qué son los trascendentales para Aquino y, en concreto, si el «Ser» es un trascendental o un «super-trascedental». La definición -dice Tomás- nos da a conocer qué es una cosa. Responde a la pregunta: ¿qué es esto? Definir es expresar la esencia de una cosa (especie) por medio el género próximo y de la diferencia específica; es decir un concepto incomplejo por medio de un concepto complejo («hombre» es «animal racional»). Esta es la definición esencial (caben otros tipos de definiciones, que ahora no interesan). A su vez, el género próximo puede reducirse a un concepto todavía más alto (en la escala de Porfirio), y así sucesivamente, hasta alcanzar aquello que sea lo más general. Esto más general es el ente y, además, aquello añadido al ente que exprese algún modo del ente que no es designado por el nombre de ente, y «que acompañe de forma general a todo ente» ${ }^{4}$. Estos modos generalísimos son «ser» (ens) y cosa (res), y sus propiedades trascendentales: «unidad», «algo», «verdad» y «bien» (unum, aliquid, bonum y verum) ${ }^{5}$. Tales modos generalísimos ya no son definibles, porque intervienen en toda definición y la hacen posible.

En consecuencia, todo lo que el hombre concibe es conocido implícitamente como «ser». Esta sería la interpretación tomasiana al famoso aforismo aviceniano: «decimos que el ser (ens), la cosa (res) y ser necesario (necesse) son tales que inmediatamente-se imprimen-en-el-alma con la primera impresión, la cual no se adquiere por medio de otras nociones». Buenaventura, sin embargo, distinguiéndose de Tomás, mantuvo que la reducción del conocimiento humano requiere todavía un paso adicional, pues lo primero cae bajo la mirada del intelecto es el acto puro, el ser divino (esse divinum ${ }^{6}$. Por otra parte, tampoco Aquino pudo seguir a Avicena en todo, porque no aceptó que ser-necesario sea, en sentido propio, una noción trascendental.

Para Aquino, la prioridad del ser tiene base ontológica, pues está fundada en su propia realidad. Aertsen considera que, a partir de tal prioridad, no se puede inferir que el «ser» sea un «super-trascendental», como lo entendía Cornelio Fabro, cuando escribía: «Ens, en la medida en que es el fundamento de los trascendentales, es el trascendental de trascendentales, o simplemente, el trascendentalizador ${ }^{7}$. Para Aertsen, la principalidad del ser con respecto a los demás trascendentales es siempre una prioridad conceptual. El ser es aquello que es concebido por el intelecto en primer lugar. Tal es - a su entender- el sentido preciso del primer artículo de las Quaestiones disputatae de veritate. Sólo así, en este sentido, el conocimiento del ser adopta un relieve particular y único. Con todo, la opinión de Fabro, que Aersten contradice, merecerá aún alguna atención por nuestra parte, algo más abajo.

Conviene que nos preguntemos ahora si la noción de pulchrum designa una propiedad trascendental del ser. Aertsen se inclina, también aquí, por seguir la opinión tomista más clásica,

3 Aertsen refiere, entre los más recientes: Armand A. MAURER, About Beauty, A Thomistic Interpretation, University of St. Thomas (Center for Thomistic Interpretation), Houston 1983; Mark D. JORDAN, The Evidence of the Transcendentals and the Place of Beauty in Thomas Aquinas, en «International Philosophical Quarterly», 29 (1989) 393-407; Pascal DASSELEER, L'étre et la beauté selon Saint Thomas d'Aquin, en Jacques FOLLON et James McEVOY (eds.), Actualité de la pensée médiévale, Éditions de l'Institut Supérieur de Philosophie, Louvain 1994, pp. 268-286. Véase el extenso trabajo de Pascal DASSELEER, Pour une métaphysique de la beauté selon Saint Thomas d'Aquin, Université Catholique de Louvain (Institut Supérieur de Philosophie), Louvain-la-Neuve 1990 (tesis doctoral).

4 De veritate, q. 1, a. 1 , in c.

5 Cfr. El excelente comentario de Jesús GARCÍA LÓPEZ, Doctrina de Santo Tomás sobre la verdad, EUNSA, Pamplona 1967; y, una exposición más sistemática: ID. Metafísica tomista. Ontología, Gnoseología y Teología natural, EUNSA, Pamplona 2001, caps. I, VI, IX y XI.

6 Itinerarium V, 3 (Quaracchi, Opera Omnia V, pp. 308-9).

7 Comelio FABRO, The Transcendentality of Ens-Esse and the Ground of Metaphysics, en «International Philosophical Quarterly», 6 (1966) 420. 
negando cualquier condición trascendental al pulchrum ${ }^{8}$. El debate sobre esta cuestión ha sido importante en las últimas décadas. Además de los autores que, desde la denuncia de Étienne Gilson, han expresado su opinión de que el pulchrum constituye realmente una propiedad trascendental en la metafísica tomasiana, otros tomistas se han aventurado todavía más, al afirmar la principalidad metafísica del pulchrum, entre las propiedades trascendentales del ser. Así, en Arte y Escolasticismo, Maritain dio fuerte impulso a esta tendencia. Él considera la belleza como «el esplendor de todos los trascendentales juntos» ${ }^{9}$. Umberto Eco también opina que la belleza es implícitamente un trascendental, aunque admita que «el texto aquiniano está lleno de incertidumbres y vacilaciones» ${ }^{10}$. Hans Urs von Balthasar afirma que en el siglo XIII «la cuestión concerniente a la trascendentabilidad de la belleza recibió una atención general» ${ }^{11}$. Tres estudiosos alemanes amplían el horizonte de sus conclusiones y procuran mostrar que la belleza tiene un lugar especial entre los trascendentales y que desempeña una función central en el pensamiento de Tomás. Así, Francis J. Kovach concluye que la belleza es «el más rico, más noble y más comprehensivo de todos los trascendentales», pues es «el único trascendental que incluye todos los trascendentales» ${ }^{12}$. Winfried Czapieswski entiende que la belleza es la unidad original de la verdad y el bien ${ }^{13}$. Gunther Pöltner considera la experiencia de la belleza como «el origen a partir del cual vive el pensamiento de Tomás». La belleza sería, pues, la unidad de las determinaciones trascendentales del ser ${ }^{14}$.

Para explicar por qué Tomás parece haber cerrado el número de los trascendentales en $D e$ veritate, sin enumerar entre ellos el pulchrum, se han elaborado una serie de hipótesis. Se ha dicho, por ejemplo, que De veritate sería obra primeriza y que sólo más tarde habría descubierto la trascendentalidad del pulchrum, al comentar el corpus dionisiano. Sin embargo, al comentar esta discusión, Aertsen afirma lo siguiente: «La única guía de nuestra investigación es la tesis de que la cuestión de la trascendentabilidad de la belleza no puede resolverse hasta que se aclare qué modo universal de ser expresa la belleza que no expresan los otros trascendentales, y cuál es su lugar en el orden de estas propiedades. El resultado de nuestro estudio resultará ser diametralmente opuesto a la tendencia dominante en la investigación moderna. La belleza no es un trascendental 'olvidado'; la visión de que es un trascendental distintivo no encuentra su apoyo en el trabajo de Tomás» ${ }^{15}$.

Ante todo conviene recordar que, siguiendo en esto a Platón, el corpus dionisiano concede la primacía al bien y no al ser. No obstante, parece que lo bello añade a lo bueno una cierta ordenación a la capacidad cognoscitiva (mientras que el bien a secas se ordenaría exclusivamente a la voluntad), de lo cual se podría deducir que el pulchrum y el bonum, siendo lo mismo en el sujeto, serían distintos sub ratione o conceptualmente, lo cual constituye precisamente el rasgo propio de la propiedad trascendental.

8 Jan A. AERTSEN, Los trascendentales en la Edad Media, cap. VIII, § 1, pp. 337 ss.

9 Jan A. Aertsen cita la traducción inglesa del original francés: Art et scholastique (1935). Cfr. Jacques MARITAIN, Art and Scholasticism, London 1939, p. 172, n. 63b. Versión castellana: Arte y escolástica, Club de Lectores, Buenos Aires 1958.

10 Umberto ECO, Il problemo estetico in Tommaso d'Aquino, Bompiani, Milano ${ }^{2} 1970$. Es la segunda edición aumentada, de la primera publicada por Edizioni di Filosofia, Torino 1956.

11 Hans Urs von BALTHASAR, Herrlichkeit. Eine theologische Aesthetik, Johannes Verlag, Einsiedeln 1965, III/I (Im Raum der Metaphysik), p. 335.

12 Francis J. KOVACH, Die Ästhetik des Thomas von Aquin, Walter de Gruyter, Berlin-New York, 1961, p. 214; ID., The Transcendentality of Beauty in Thomas Aquinas, en Paul WILPERT (ed.), Metaphysik im Mittelalter. Ihr Ursprung und ihre Bedeutung, Walter de Gruyter («Miscellanea Mediaevalia», 2), Berlin 1963, p. 392.

13 Winfried CZAPIEWSKI, Das Schöne bei Thomas von Aquin, Herder, Wien-Basel-Freiburg 1964.

14 Gunther PÖLTNER, Schönheit. Eine Untersuchung zum Ursprung des Denkens bei Thomas von Aquin, Herder, Wien-Basel-Freiburg 1978, p. 76.

15 Jan A. AERTSEN, Los trascendentales en la Edad Media, cap. VIII, § 1. 
Es innegable que lo bueno y lo bello son de algún modo convertibles; pero, la condición de la trascendentalidad es que lo bello y el ser sean convertibles (no que lo sean lo bueno y lo bello). No entra en la consideración de Tomás de Aquino, cuando estudia el corpus dionisiano, como Aertsen ha puesto de manifiesto, la convertibilidad entre bueno y el ser. Por ello, según Aertsen, el Aquinate no considera que el pulchrum sea un trascendental. La belleza no expresa, según Tomás, un modo general de ser que los otros trascendentales no expresen. Se trata sólo de una especificación del bien, no del ser.

Por las mismas fechas, más o menos, en que comentaba el corpus dionisiano, Aquino redactaba (o había terminado) su primera parte de la Summa theologiae. Allí, al preguntarse por qué agradan las cosas bellas, había señalado: «Lo bello se refiere al poder cognoscitivo, pues se llama bello aquello cuya vista agrada, y por esto la belleza consiste en la debida proporción, ya que los sentidos se deleitan en las cosas debidamente proporcionadas como algo semejante a ellos, pues los sentidos, como toda facultad cognoscitiva, son de algún modo entendimiento [ratio] $\rangle^{16}$. Está claro que habla de los sentidos y no de la voluntad ni de la inteligencia; y parece también evidente que se refiere a un accidente (la proporción), es decir, a un modo particular de ser y no a un modo generalísimo, pues también son las cosas que no son proporcionadas. La proporción es un subpredicamento de la cualidad, encuadrado en el par forma-figura ${ }^{17}$.

El binomio forma-figura es tan interesante, que merece alguna atención ${ }^{18}$. La figura es una cualidad de las substancias corpóreas. No es la extensión (partes extra partes, como decían los latinos), que simplemente expresa la cantidad, sino que se refiere a la disposición de las partes. La figura o perfil se distingue, pues, de la extensión, pues un cuerpo con la misma extensión puede tener distintos perfiles. Si la figura tiene la proporción conveniente, se habla de la forma, que indica la formositas (esta «forma» se distingue de la forma esencial, de la forma substancial y de la noción de forma accidental). Es evidente que la hermosura es la belleza de las substancias corpóreas. Esta proporción de formas, naturales o artificiales, es estudiada por la teoría del arte. Sólo en sentido muy amplio o metafórico se puede hablar de proporción en las substancias incorpóreas. Un ángel, por tanto, sólo se dirá bello si se aparece corporalmente. Dios es bello por analogía extrínseca de proporcionalidad impropia.

Los subpredicamentos forma-figura nos acercan a una noción revelada muy importante: el tema de la imagen. Ya se dijo que, por ser forma y figura qualitates circam quantitatem se refieren in recto a las cosas corpóreas. No obstante, como ha señalado muy atinadamente Elisabeth Reinhardt, glosando a Tomás, «no supone contradicción, ni siquiera imprecisión, el hecho de que [Aquino], cuando se refiere al contenido de la imitación propia de la imagen, hable de la cualidad y de una adecuación en aquella cualidad, porque la cualidad en cuanto modus substantiae y en cuanto accidente 'figura' manifiesta la especie»" ${ }^{19}$. Por ello se puede

16 El texto completo dice: «Pulchrum et bonum in subiecto quidem sunt idem, quia super eandem rem fundantur, scilicet super fomam: et propter hoc, bonum laudatur ut pulchrum. Sed ratione differunt. Nam bonum proprie respicit appetitum: est enim bonum quod omnia appetunt. Et ideo habet rationem finis: nam appetitus est quasi quidam motus ad rem. Pulchrum autem respicit vim cognoscitivam: pulchra enim dicuntur quae visa placent. Unde pulchrum in debita proportione consistit: quia sensus delectatur in rebus debite proportionatis, sicut in sibi similibus; nam et sensus ratio quaedam est, et omnis virtus cognoscitiva. Et quia cognitio fit per assimilationem, similitudo autem respicit formam, pulchrum proprie pertinet ad rationem causae formalis» (Summa theologiae, I q5 a4 ad1). En cursiva el pasaje expresamente aludido por Aertsen.

17 Los subpredicamentos de la cualidad son cuatro, agrupados en pares, según su mayor o menor inhesión en la substancia: forma y figura, hábito (entitativo u operativo) y disposición, pasión y cualidad pasible, potencia e impotencia.

18 Cfr. Antonio MILLÁN-PUELLES, Léxico filosófico, Rialp, Madrid 1984, pp. 203-204.

19 El texto citado por la Prof. Reinhardt es: «Non in imitatione quorumcumque exteriorum est ratio imaginis; sed eorum quae sunt signa quodammodo speciei et naturae; et ideo posuit speciem potius quam qualitatem» ( $I$ Sent., d.28, q3, a1, ad1). Cfr. Elisabeth REINHARDT, La imagen de Dios en el hombre. La «imago creationis» según Santo Tomás de Aquino, en «Excerpta e dissertationibus in Sacra Theologia [Universidad de Navarra]», 9 (1985) 379-466, aquí pp. 401-402. 
decir propiamente que el hombre o el ángel son imagen de Dios, porque lo son secundum speciem.

Después de las anteriores aclaraciones podemos volver a la tesis de Jan A. Aertsen. Según Aertsen, Aquino no trata en ningún lugar la belleza por sí misma. Tomás no consideró, como algunos han pretendido, que el pulchrum sea «el más rico y noble» de todos los trascendentales. La estética, como una disciplina filosófica independiente, sólo se planteó en el siglo XVIII. Fue en el periodo post-medieval, en efecto, cuando se desarrolló por vez primera la tríada «verdad-bien-belleza». Este desarrollo alcanzó su culminación en Kant, en el proyecto de sus tres Críticas (razón pura, razón práctica y juicio). Por consiguiente, Aertsen concluye que en la medievalística se aprecia cierto anacronismo, fomentado por Jacques Maritain, que proyecta el desarrollo de la estética ilustrada hacia el pasado. De este modo, se da una importancia a la belleza que nunca tuvo para el propio Tomás, y se pretende desarrollar una estética filosófica basada en los principios escolásticos, que no corresponde a los intereses de la época, al menos en el ámbito cristiano.

Como se sabe, Immanuel Kant inauguró la consideración estética del juicio ${ }^{20}$. La facultad de juzgar - son casi sus palabras literales- proporciona el concepto mediador entre los conceptos de la naturaleza y el concepto de la libertad, que hace posible el paso de la razón pura teórica a la razón pura práctica. Pues bien; cuando se produce una concordancia de la forma del objeto dado con la facultad cognoscitiva, sin que tal forma se refiera a un concepto predeterminado, entonces la forma constituye el fundamento de un placer que viene de la representación del objeto. Lo bello modera y dispone un paso armonioso entre lo sensible y lo inteligible. El gusto hace posible el paso armonioso de la atracción sensible al interés moral habitual. Cuando juzgamos que la representación va necesariamente acompañada por este placer y que tal sensación placentera va a tener carácter universal, nos hallamos ante un juicio estético ${ }^{21}$. El juicio teleológico viene después, con posterioridad genético-intencional: consiste en la concordancia de la forma de un objeto dado con la posibilidad de la cosa misma, según un concepto previo de la cosa. Tal concepto previo se basa precisamente en la forma ${ }^{22}$.

Ruiz Retegui ha visto el tema con suma perspicacia en un pequeño y denso opúsculo ${ }^{23}$. Distingue dos respuestas fundamentales al problema de la belleza. Para unos, la belleza es un fenómeno «autónomo» e independiente de las demás dimensiones de la realidad, «como algo perteneciente a la manera de aparecer o al modo cómo las cosas son mostradas». Esta consideración se aplica preferencialmente a la belleza artística, es decir, a la obra realizada por el hombre, y se abrió camino a partir del siglo XVII. Así se habla de las «bellas artes» ${ }^{24}$. Kant fue la culminación de tal proceso. Otra respuesta, que Ruiz Retegui denomina «respuesta tradicional», y a la cual se apunta, considera el pulchrum como una propiedad del ser en cuanto

20 Cfr. María Antonio LABRADA, Belleza y racionalidad. Kant y Hegel, EUNSA, Pamplona 1990; y Bernard BOURGEOIS, Lo bello y el bien en Kant, en «Anuario Filosófico», 26 (1993) 139-153.

21 ¿No habrá aquí alguna continuidad entre la «sensación placentera» kantiana (el estar a gusto) y la luz de la evidencia ockhamiana, provocada por noticia intuitiva cuando se dan simultáneamente la presencia (al intelecto) y la existencia (extramental) del objeto?

22 Dejemos de lado, porque nos apartaría de nuestro propósito, el hecho de que el juicio estético se desvanezca en el juicio teleológico. La paradoja kantiana consiste precisamente en que lo bello es incognoscible.

23 Antonio RUIZ RETEGUI, Pulchrum. Reflexiones sobre la Belleza desde la Antropologia cristiana, Rialp, Madrid 1998, pp. 12-13.

24 En esta corriente se inscribe el interesante estudio de Mariateresa FUMAGALLI BEONIO BROCCHIERI, L'estetica medievale, Il Mulino ( «Lessico dell'estetica»), Bologna 2002. La autora, que dedica un capítulo a «La bellezza secondo i filosofi», trata el tema filosófico en la perspectiva dionisiana, y se sitúa en el ámbito del ejemplarismo y se adhiere a las tesis de Umberto Eco, al presentar la síntesis tomasiana, señalando que Tomás de Aquino habría descrito la belleza como integritas, proportio y claritas. Ya hemos recogido la discusión de Aertsen, que nos parece muy rigurosa, a la hipótesis de algunos medievalistas, según la cual Aquino se habría sensibilizado al tema del pulchrum, incluyéndolo en su relación de trascendentales, al entrar en contacto con el corpus dionisiano. 
ser, pero no un trascendental en sentido propio, sino como un trascendental «dependiente», que se define como «esplendor de lo verdadero», «esplendor de lo bueno» e, incluso, «esplendor de la unidad» ${ }^{25}$. Se trata de una solución semejante, pero no equivalente, a la ofrecida por Francis J. Kovach y Winfried Czapieswski, en los pasados sesenta. De este modo, Ruiz Retegui asume la doctrina tomasiana más clásica, que considera cerrada la enumeración de los trascendentales, y entronca, al mismo tiempo, con la corriente inaugurada por Fabro, que abre en la citada enumeración algunas determinaciones que la completan y enriquecen. Cabría hablar, por consiguiente, del ser como un «super-trascendental», por su prioridad genético-conceptual (¿acaso no hay aquí una cierta dependencia entre esta noción fabriana y el juicio estético kantiano?); y, al mismo tiempo, cabría considerar a la belleza como un «trascendental-dependiente», que sin ser un trascendental en sentido propio (puesto que su condición es subpredicamental), se sitúa sin embargo en la línea de los trascendentales.

Vistas así las cosas, ¿qué decir de,la belleza, en la estética musulmana medieval, tal cómo ha sido recapitulada por Joaquín Lomba? ${ }^{26}$.

\section{DE LA RATIO A LA IMAGINATIO (EN LA FILOSOFÍA MUSULMANA)}

Lomba ha recapitulado con precisión y acierto los tres niveles de la realidad, si así se puede hablar: el nivel supremo o trascendente; el nivel «imaginal», carente de espacio y de tiempo, que Lomba describe como el mundo metahistórico, propio de la imaginación; y el nivel nuestro o tercero, el de la razón, en el que la realidad del Uno se expresa espacio-temporalmente, y en el que se desarrollan las explicaciones científicas. El tránsito del mundo racional al mundo imaginal es la constante tentación del espacio reflexivo musulmán, porque sólo en el imaginal es posible el encuentro con la perfección estética.

El tema del ascenso, común a todas las filosofías, también a la de Santo Tomás (no se olvide que los trascendentales requieren, de algún modo, un ascenso, trascendiendo todo lo concreto hasta lo generalísimo), tiene en la filosofía musulmana las características del fondo medioplatónico del Bajo Imperio, sobre todo neoplatónicas. El corpus dionisiano no había escapado a la fascinación de los ascensos y descensos, en un mundo en que lo más alto era el bien apetecido, más allá del ser, es decir, el Uno inefable. En todo caso, la filosofía musulmana del siglo XIII de nuestra Era (y ya antes) aspiraba a alcanzar la belleza más allá de la racionalidad, cosa que Santo Tomás no podía aceptar, puesto que más allá de la razón no hay nada, desde el punto de vista cognoscitivo.

Un texto aportado por Lomba, tomado de Hazim al-Qartâyannî (1211-1285), contemporáneo de Aquino, aunque desconocido por éste, es muy expresivo:

«El deleite que siente el alma con lo imaginario es muy superior al que siente al contemplar el original. La estatua y la persona retratada provocan una emoción diferente; la primera agita el alma asombrando por la belleza de sus imitaciones y por la invención técnica, al hacer posible su imitación, mientras que la persona real, si es bien parecida, agitará las almas por el amor hacia su propia hermosura».

25 La imago se relaciona con la unidad (el trascedental unum) a través de la similitudo («quaedam unitas est»), que es condición previa de la imago, y es consecuencia —en el orden operativo- de la imago. Cfr. TOMÁS DE AQUINO, Summa theologiae, I q93 a4c. Véase: Elisabeth REINHARDT, La imagen de Dios en el hombre: la «imago creationis» según Santo Tomás de Aquino, Universidad de Navarra, tesis doctoral, Pamplona 1977, pro manuscripto, cap. III («Similitudo»), pp. 238 ss.

26 Seguiremos el último de sus estudios, que revelan su exposición más madura, titulado: Razón e imaginación en la estética musulmana medieval, ponencia presentada en el XI Congreso Internacional de Filosofía Medieval, celebrado en Oporto (agosto de 2002), que se publicará en las actas del Congreso. 
Más expresivo es, si cabe, otro pasaje anterior en el tiempo, también recogido por Lomba, tomado del gran poeta andalusí Ibn Hazm de Córdoba (994-1065) ${ }^{27}$ :

«[...] se me ha pedido una explicación exacta de las clases de belleza de las formas. Y digo que: La dulzura es la finura de los rasgos y la gracia de los movimientos y la ligereza de los gestos y la adaptación del alma a los accidentes de las formas, aunque no sean bellas. La corrección de las formas externas es la hermosura de cada una de las cualidades aisladas, aunque muchas veces la hermosura de cualidades aisladamente consideradas sea fría de aspecto. El brillo de los miembros externos va con la hermosura que hay en ellos y es la vivacidad y la soltura. La belleza es algo que no tiene en la lengua nombre, aunque es sentido en las almas por el acuerdo de todo el que lo ve y es una túnica que reviste el rostro y una claridad que inclina los corazones hacia sí, de modo que las opiniones son concordes en aprobarlo a pesar de que no haya cualidades hermosas, puesto que el que lo ve le rinde le alma, le gusta a su corazón, aunque, si contemplara aisladamente las cualidades, no encontraría mérito. Parece como si fuera algo que hay en el alma de lo visto, percibido por el alma del que lo ve. Esta es la cumbre de las categorías de la belleza».

El deleite estético no se alcanza en el mundo de la razón cognoscitiva, sino en el ámbito del imaginario

Esta espléndida descripción de Ibn Hazm, aparentemente sólo fenomenológica de la belleza, ha sido bien sintetizada por Joaquín Lomba, destacando:

a) que el texto se refiere sobre todo a la belleza humana, aunque se puede extender a la belleza natural y a la belleza artificial.

b) que es notable la importancia concedida a la luz, un tema reiterado en la filosofía medieval de corte platónico, que alcanzará un particular relieve en la filosofía de Roberto Grosseteste, maestro de los franciscanos en la Inglaterra del siglo XIII.

c) que acentúa la movilidad y ligereza de toda forma bella.

d) que distingue entre la pura corrección formal y la calidad estética, y entre cualidades aisladamente consideradas y la armonía que unas cualidades aisladas no bellas pueden alcanzar en el conjunto.

e) y, finalmente, que aprecia que la belleza auténtica es algo misterioso que no se percibe sólo por los sentidos, sino con toda el alma, en un contacto intimo entre el admirador y lo contemplado.

Parece, pues, que la filosofía musulmana, al menos en los tiempos de los dos califatos, tampoco consideró el tema del pulchrum en el ámbito metafísico, como si se tratase de una propiedad trascendental. Más bien apeló al análisis categorial, o sea, a la consideración de la belleza en el marco de los subpredicamentos (la forma o figura), y a la imaginación, más que a la ratio, como potencia «cognoscitiva» que se compromete particularmente en la contemplación de la belleza y su percepción. Como Aquino, los musulmanes entendieron que la belleza tiene que ver con la apreciación sensitiva (sentidos externos o internos) y con la disposición armónica de la extensión o formositas. No se olvide que la percepción del movimiento corresponde a los sentidos internos, como también es cosa de éstos la apreciación de la unidad armónica.

En tal proceso cognoscitivo, si se me permite esta licencia expresiva, la imaginación juega un papel relevante, porque la imaginación crea las imágenes. La imaginación supone ir más allá

27 Sobre las doctrinas estéticas de este pensador musulmán, cfr. Joaquín LOMBA, La beauté objetive chez Ibn Hazm, en «Cahiers de Civilisation Médiévale», 7 (1964) 1-18 y 161-178; e ID., Ibn Hazm o el misterio de la belleza, en «Miscelánea de Estudios Árabes y Hebraicos», 38 (1990) 117-139. 
de lo meramente percibido, incluso superando, al menos según la filosofía musulmana, la mera adecuación entre la cosa y el intelecto (supuesta la cogitativa), que es el conocimiento racional. La imaginación permite, en definitiva, superar las formas sublunares y adentrarse en el mundo de los arquetipos.

Es interesante considerar aquí los escritos esotéricos de Avicena, quien, por otra parte, puso también las bases de la doctrina de los trascendentales, con su famoso postulado de las tres primeras nociones (ser, cosa y ser-necesario), que antes hemos recordado.

Pues bien; en su Risâlâ de Hayy B. Yaqzân (Relato de Hayy B. Yaqzân) ${ }^{28}$, Ibn Sînâ sitúa la belleza en el Occidente, en la tercera esfera, que es la de Venus: «cuyos habitantes gozan de singular belleza» y «poseen un gusto refinado para los instrumentos musicales»; «una inclinación natural los conduce al bien y a la belleza». No obstante, el goce pleno, «el don de la dulzura de carácter y el encanto y sutileza de su espíritu [...] y el privilegio de ser el término final de toda perfección [...]», el estar, «dotados de un aspecto fascinante, una belleza que hace palpitar de admiración, una figura que ha alcanzado su cénit», está al Oriente. En el Oriente se encuentra el Sol naciente, más allá del país de los demonios, incluso después de haber superado el país de los ángeles, en la comunidad del gran Rey. Por el contexto, es evidente que se viaja al Occidente y, sobre todo, al remoto Oriente, no con la razón, sino por la imaginación.

Esto queda aclarado en el Risâlâ del pájaro ${ }^{29}$. En este magnífico relato esotérico se cuenta un extraño secreto: cómo puede el alma salir de sí misma, de su condición natural en la que se halla encadenada, para alcanzar unos espacios nuevos, donde los goces son inefables, después de su liberación (aunque no total ni completa, pues resta algún encadenamiento imposible de romper). En esos espacios superiores está el Gran Rey, de una hermosura fascinante. También en este Risâlâ es sólo la imaginación la única que procede con verdadera libertad, permitiendo salir de la jaula donde estamos aprisionados.

\section{CONCLUSIONES}

Hemos comprobado que Aquino no descubrió una vía analítica que le condujera hacia el pulchrum como trascendental, quizá porque esa vía no existe. La Metafísica puede alcanzar, a lo sumo, el pulchrum como un «trascendental-dependiente» (un especie de subtrascendental) del bien, de la verdad y de la unidad. En tal contexto, la belleza es como el esplendor de esos trascendentales. Sin embargo, su fino análisis de la imago, como algo que excede la esfera subpredicamental, aunque en íntima conexión con ella, permite trascender el plano físico (por así decir) y entrar en el mundo de la ejemplaridad, que se halla en otra dimensión.

Los coetáneos musulmanes apelando a la imaginación, como superación de los límites de la ratio, recurrieron (?) a la vía esotérica que nos adentra en el mundo de los ejemplares, donde la belleza también ha rebasado los estrechos marcos de la condición física sublunar. Bien claro, a pesar de lo dicho, que tal vía no es plenamente satisfactoria, puesto que la liberación del alma terrena no es posible por completo por la vía imaginaria. Siempre queda un cepo en los pies, como destaca agudamente Avicena en su Risâla del pájaro.

En ambos casos, por tanto, la apreciación y el goce estético implican trascender la vía racional. Aquino advirtió que el pulchrum es captado por el sensus, asimilando (en este caso) el sensus a la ratio: «nam et sensus ratio quaedam est», dice para nuestro asombro. Lo musulmanes, en cambio, se abandonaron abiertamente al sensus, o sea, al sentido, fundando una cul-

28 Edición española (traducción, estudio preliminar y notas) de Miguel Cruz Hernández en: AVICENA, Tres escritos esotéricos (con el resumen de otro perdido y un capítulo espiritual), Tecnos («Colección Clásicos del Pensamienton, 129), Madrid 1998, pp. 3-32.

29 Ibidem, pp. 33-48. 
tural fuertemente sensual. La sensación fue la vía elegida para trascender el estrecho orden racional (sic).

No obstante, los filósofos musulmanes advirtieron que la imaginación libera, pero no del todo; permite huir de la cárcel de esta vida, aunque con un cepo en los pies. ¿Será acaso esta sutil restricción una advertencia de que el mundo imaginal no es real? En tal perspectiva, ¿será la belleza un imposible soñado o puramente imaginado? ¿Será sólo una experiencia reservada a la poesía? El pulchrum, ¿no será más bien el trascendental inexistente, que el trascendental preterido u olvidado? El goce estético perfecto, ¿será un «realmente» un imposible aquí abajo?

Josep-Ignasi Saranyana Instituto de Historia de la Iglesia

Universidad de Navarra 31080 Pamplona E-mail: saranyana@unav.es 